\title{
Efficacy of an Innovative Device in Reducing Discomfort during Local Anesthesia Administration in Children: A Clinical Study
}

\author{
Priya Subramaniam ${ }^{1}$, Simerleen K Ghai ${ }^{2}$
}

\begin{abstract}
Aim and objective: To assess the efficacy of an innovative vibrating device and compare it with the conventional method in reducing discomfort during the administration of local anesthesia.

Materials and methods: Forty children in the age-group of 4-8 years requiring local anesthesia for routine dental procedures were allocated to either a control or experimental group, with 20 children in each group. The preoperative assessment of behavior was carried out using the Frankl Behavior Rating Scale. Both groups received local anesthesia using the intraoral conventional approach. However, in the experimental group, a vibrating device was simultaneously placed over the cheek during local anesthesia administration. The SEM (sounds, eyes, motor) scale was used to assess the level of comfort or pain during the administration of local anesthesia. Data were subjected to statistical analysis and the level of significance was considered at $5 \%$.

Results: The mean SEM score in the control group was $6.65 \pm 21.95$ which was significantly higher than $3.80 \pm 1.15$ in the experimental group $(p<0.001)$.

Conclusion: The vibrating device was useful and effective in reducing pain and discomfort during intraoral local anesthesia administration.

Keywords: Local anesthesia, SEM scale, Vibrating device.

International Journal of Clinical Pediatric Dentistry (2021): 10.5005/jp-journals-10005-1948
\end{abstract}

\section{INTRODUCTION}

Management of pain and anxiety is of paramount importance in pediatric dentistry. On experiencing pain during dental treatment, children exhibit behavioral problems, which necessitate the implementation of appropriate behavior management protocols. ${ }^{1}$ The injection of local anesthesia remains one of the most fear and anxiety-inducing and painful procedures in pediatric dentistry. ${ }^{2,3}$

The pain of injection in pediatric patients may result in longterm negative consequences, such as fear and anxiety, causing a negative influence on the behavior, comfort, and cooperation of the child during subsequent dental visits. ${ }^{4}$

To reduce the discomfort associated with dental injections, several pharmacological and alternative delivery methods have been carried out. ${ }^{5}$ The use of lidocaine patches, topical anesthetics, and anxiolytic drugs have their limitations. ${ }^{6,7}$ Although topical anesthetics and lidocaine patches are effective on surface tissue, their application still does not provide a completely painless injection. ${ }^{8}$ Anxiolytic drugs can add to the appointment time, have adverse effects, and come with increased legal risks. ${ }^{9}$

The newer methods include computerized delivery systems, such as "The Wand" CompuDent system, Jet-injection, vibrotactile devices such as Vibraject and DentalVibe. ${ }^{1,5,8,10}$ All these systems require the use of sophisticated technology and are expensive, thereby increasing the cost of dental treatment. The search continues for an affordable system that can reduce discomfort associated with needle insertion and thereby reduce dental fear in children.

Vibration stimulus is one of the non-pharmacological methods used to diminish the pain and discomfort associated during administration of local anesthesia. The "gate control"

\begin{abstract}
1,2Department of Pedodontics and Preventive Dentistry, The Oxford Dental College and Hospital, Bengaluru, Karnataka, India

Corresponding Author: Priya Subramaniam, Department of Pedodontics and Preventive Dentistry, The Oxford Dental College and Hospital, Bengaluru, Karnataka, India, Phone: +91 9844225624, e-mail: drpriyapedo@yahoo.com

How to cite this article: Subramaniam P, Ghai SK. Efficacy of an Innovative Device in Reducing Discomfort during Local Anesthesia Administration in Children: A Clinical Study. Int J Clin Pediatr Dent 2021;14(3):353-356.
\end{abstract}

Source of support: Nil

Conflict of interest: None

theory of Melzack and Wall proposed in 1965 suggests that the pain experience can be reduced by activation of nerve fibers that conduct non-noxious stimuli. ${ }^{11}$ The incorporation of this theory would prove to be advantageous in the very sensitive orofacial region where more than a third of the cells in the somtosensory cortex of the brain are devoted to sensory inputs from the mouth. ${ }^{12}$ In the orofocial region, vibration stimuli can be used to raise the pain threshold and relieve pain of dental origin. ${ }^{13}$

A commercially available device, "BUZZY" (MMJ Labs, Atlanta, GA, USA) has been invented by Amy Baxter, an emergency pediatrician and pain researcher. This device has successfully shown to decrease pain and enhance patients' compliance during venous blood collection, venipuncture, intramuscular, and intravenous injections. ${ }^{14-17}$ However, there is only one published report on the use of this device in children during local anesthesia administration for routine dental procedures. Although the device proved to be 
effective in reducing pain and anxiety, there were several limitations of the study. ${ }^{18}$

Therefore, this study aimed to assess the efficacy of an innovative and indigenous extraoral vibrating device in reducing discomfort during the administration of local anesthesia in children and to compare it with the conventional method of local anesthesia administration.

\section{Materials and Methods}

The study was conducted in the Department of Pedodontics and Preventive Dentistry. Ethical approval to conduct the study was obtained from The Institutional Ethics Committee (number). Before the study, the nature of the study protocol was described to the parent. Written consent was obtained from the parents for the participation of their children in the study.

The sample size calculation was performed using the G Power software v.3.1.9.2. Considering the effect size to be measured $(d)$ at $80 \%$ for the two-tailed hypothesis, the power of the study at $80 \%$, and the margin of error at $10 \%$, the total sample size was estimated to be 40 .

\section{Sample Selection}

The inclusion criteria were:

- Children aged 4-8 years requiring routine dental procedures to be carried out under local anesthesia.

- Children of parents who were willing for them to participate in the study.The exclusion criteria were:

- Children who had previously received local anesthesia.

- Children who presented with a history of hospitalization, chronic illness, or lacking the cooperative ability.

- Children who required treatment under sedation/general anesthesia.

Forty children were randomly assigned by the toss of a coin to group I (control) and II (experimental) with 20 children in each group. The preoperative behavior of each child was assessed using Frankl Behavior Rating Scale (1962). ${ }^{19}$ For all dental procedures, $2 \%$ lignocaine containing 1:200,000 adrenaline was used as the local anesthetic agent. For nerve block injections, a 26-G $13 \mathrm{~mm}$ needle and for local infiltration, a 31-G $6 \mathrm{~mm}$ needle was used. All injections were performed by one operator using standardized

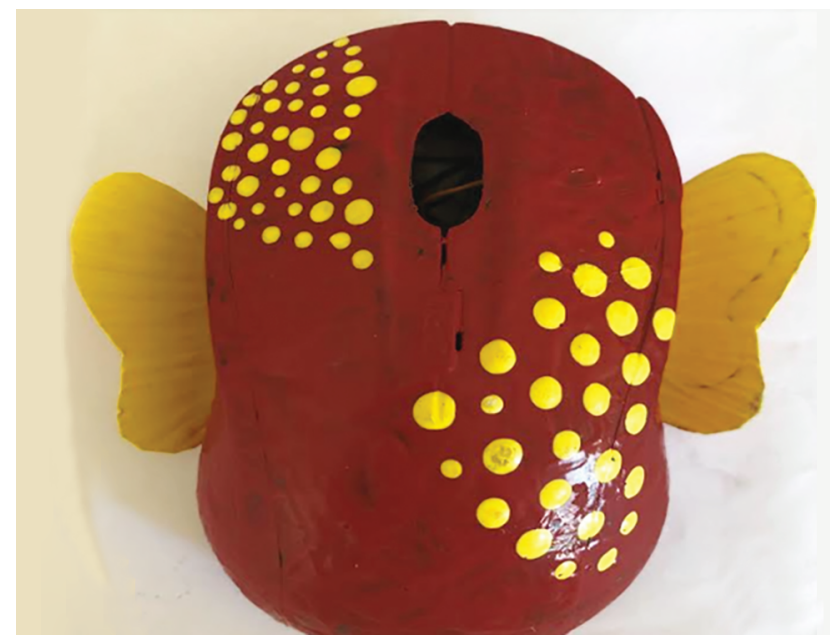

Fig. 1: Vibrating device technique in order to control operator related variables such as previous experience and technical expertise. Anesthetic solution was administered at a constant rate of 30-40 seconds. ' For children in group II, an innovative indigenous vibrating device was placed externally over the cheek during local anesthesia administration in all children (Fig. 1). During inferior alveolar nerve block technique, the device was placed over the ramus of the mandible. ${ }^{20}$ For maxillary buccal supraperiosteal technique, it was placed against the zygomatic arch of the maxilla.

The device was prepared indigenously using the hardware of an existing computer mouse. The left and right switches were used intact with a small size DC 3 voltage motor to produce vibrations of $50 \mathrm{~Hz}$ frequency. The vibrations were not associated with the production of an electromagnetic field (Fig. 2).

During the administration of local anesthesia administration, the child's pain and discomfort was assessed by the SEM scale. ${ }^{21}$ This scale includes three types of observations; sounds, eyes and motor. The level of response for each observation is given a numerical value ranging from 1 to $4^{21}$ (Table 1).

Data obtained were statistically analyzed using Statistical Package for Social Sciences (SPSS) for Windows (Version22.0. Released2013. Armonk, NY: IBM Corp.). The age and gender distribution among the study subjects were carried out using the Mann-Whitney $U$ test and Chi-square test, respectively. The comparison of the Frankl Behavior Rating Scale was done using Chisquare test independent Student's $t$-test was used to compare the mean SEM scale scores between the 2 groups. Level of significance was set at $p \leq 0.05$.

\section{Results}

The age and gender-wise distribution were similar in both groups. The mean age of children in the control group was $6.7 \pm 1.3$ years which was slightly more than the experimental group $(6.1 \pm 1.4$ years) with no significant difference $(p=0.12)$. There were $12(60 \%)$ males and 8 (40\%) females in the control group and 11 (55\%) males and $9(45 \%)$ females in the experimental group $(p=0.75)$ (Table 2$)$.

The preoperative assessment of the behavior using the Frankl Behavior Rating Scale in-between the two groups did not show a significant difference ( $p=0.33$ ) (Table 3 ).

In the comparison of the mean SEM score and its individual components, it was significantly less in group II. The mean score

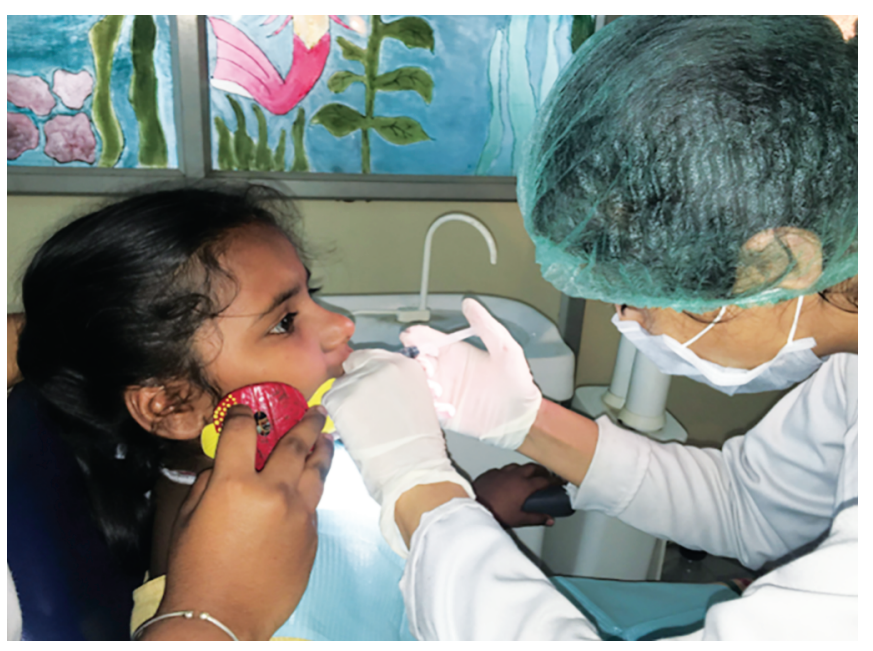

Fig. 2: Extraoral placement of vibrating device during administration of inferior alveolar nerve block 
Discomfort-reducing Device for Local Anesthesia Administration

Table 1: SEM (sounds, eyes, motor) scale

\begin{tabular}{|c|c|c|c|c|}
\hline Observations & 1. Comfort & 2. Mild discomfort & 3. Moderately painful & 4. Painful \\
\hline Sounds & No sounds indicating & Non-specific sounds, & $\begin{array}{l}\text { Specific verbal sounds, e.g., "OW" } \\
\text { raises voice }\end{array}$ & Verbal complaint, e.g., scream, sobbing \\
\hline Eyes & $\begin{array}{l}\text { No eye signs of dis- } \\
\text { comfort }\end{array}$ & $\begin{array}{l}\text { Eyes wide, show } \\
\text { concern, no tears }\end{array}$ & Watery eyes, eyes flinching & Crying, tears running down the face \\
\hline Motor & $\begin{array}{l}\text { Hands relaxed, no ap- } \\
\text { parent body tenseness }\end{array}$ & $\begin{array}{l}\text { Hands show some } \\
\text { distress, grasps chair }\end{array}$ & $\begin{array}{l}\text { Random movement of arms or } \\
\text { body without the aggressive } \\
\text { intention of physical contact }\end{array}$ & $\begin{array}{l}\text { Movement of hands to make } \\
\text { aggressive physical contact, e.g., } \\
\text { punching, pulling the head away }\end{array}$ \\
\hline
\end{tabular}

Table 2: Age- and gender-wise distribution between the groups

\begin{tabular}{|c|c|c|c|}
\hline \multirow[b]{2}{*}{ Groups } & \multirow{2}{*}{$\begin{array}{l}\text { Age (years) } \\
\text { Mean } \pm S D\end{array}$} & \multicolumn{2}{|c|}{ Gender } \\
\hline & & Male $n(\%)$ & Female $n(\%)$ \\
\hline Group I (control) $(n=20)$ & $6.7 \pm 1.3$ & $12(60)$ & $8(40)$ \\
\hline $\begin{array}{l}\text { Group II (experimental) } \\
(n=20)\end{array}$ & $6.1 \pm 1.4$ & $11(55)$ & $9(45)$ \\
\hline$p$ value & $0.12^{\mathrm{a}}$ & & $75^{b}$ \\
\hline
\end{tabular}

${ }^{a}$ Mann-Whitney $U$ test

${ }^{\mathrm{b}} \mathrm{Chi}$-square test

Table 3: Comparison of Frankl behavioral rating scale between the groups (Chi-square test)

\begin{tabular}{|c|c|c|c|}
\hline \multirow{2}{*}{$\begin{array}{l}\text { Frankl behavioral } \\
\text { rating scale }\end{array}$} & \multicolumn{2}{|r|}{ Group } & \multirow[b]{2}{*}{$p$ value } \\
\hline & Group I (control) & Group II (experimental) & \\
\hline $\begin{array}{l}\text { Definitely } \\
\text { negative }\end{array}$ & $4(20 \%)$ & $6(30 \%)$ & 0.33 \\
\hline Negative & $7(35 \%)$ & $3(15 \%)$ & \\
\hline Positive & $9(45 \%)$ & $11(45 \%)$ & \\
\hline $\begin{array}{l}\text { Definitely } \\
\text { positive }\end{array}$ & $0(0 \%)$ & $0(0 \%)$ & \\
\hline
\end{tabular}

Table 4: Comparison of mean SEM scale scores between the groups (independent Student's $t$-test)

\begin{tabular}{lllll}
\hline Variable & Group & Mean \pm SD & Mean difference & $p$ value \\
\hline Sound & Control & $2.00 \pm 0.92$ & 0.85 & $<0.001^{*}$ \\
& Test & $1.15 \pm 0.32$ & \\
Eyes & Control & $2.45 \pm 0.61$ & 1.15 & $<0.001^{*}$ \\
& Test & $1.30 \pm 0.57$ & \\
Motor & Control & $2.20 \pm 0.70$ & 0.85 & $<0.001^{*}$ \\
& Test & $1.35 \pm 0.48$ & \\
SEM & Control & $6.65 \pm 1.95$ & 2.85 & $<0.001^{*}$ \\
& Test & $3.80 \pm 1.15$ & \\
\hline
\end{tabular}

$p<0.05$ is significant

for the sounds component was $2.00 \pm 0.92$ and $1.15 \pm 0.37$ in groups I and II, respectively. Similarly, the mean score for the eyes component was $2.45 \pm 0.61$ and $1.30 \pm 0.57$, and the motor component was $2.20 \pm 0.70$ and $1.35 \pm 0.49$ in groups I and II, respectively. The mean SEM score was significantly higher (6.65 \pm $1.95)$ in the control group than in the experimental group $(3.80 \pm$ 1.15) $\left(p<0.001^{*}\right)$ (Table 4).

\section{Discussion}

There is a definitive need to find an efficient and cost-effective device to decrease the pain and discomfort associated with needle insertion. The use of vibrating devices, with or without the application of external cold, has gained attention in both the dental and medical fields to reduce the pain of injections.

Reports on the effect of vibration in the form of an intraoral device and its impact on pain during local anesthesia administration have given conflicting results. The use of VibraJect resulted in significantly less pain perception, but there was no significant difference in physiological parameters. ${ }^{5}$ Intraoral vibratory devices (Vibraject and DentalVibe) have shown varying levels of pain during local anesthesia administration, with a few of these studies involving older children who required only infiltration technique of local anesthesia administration. 1,8,22

In comparison to the other intraoral vibrating devices, the device used in our study was placed extraorally over the cheek and was less fear-provoking. The device was indigenously structured using a computer mouse and its appearance was camouflaged to resemble a butterfly or a ladybird. This colorful device was well accepted by children. The Tell-show-do technique was applied to familiarize the children with the device. They were allowed to hold and feel the vibration over their hands, before placing it over the cheek.

The vibratory device used in this study works on a similar principle as that of the commercially available extraoral BUZZY, which is designed to also incorporate the application of ice packs. However, the device used in this study did not require lowering of surface temperature as the additional use of an ice pack in young, anxious children could cause discomfort with limited acceptance.

The mean age of children in both the groups exhibited a comparable distribution thus indicating a similar level of cognitive development. Cognition implies an awareness of internal and external environmental influences on oneself and can help one to gain control over those influences. ${ }^{23}$ Fear has been reported to be more among females. ${ }^{24}$ In this study, however, there was no significant difference in the SEM scores between males and females, thus indicating no gender bias. Needles and injections can provoke fear in children, irrespective of their level of cooperation. Therefore, children belonging to all categories of the Frankl Behavioral Rating scale were included in the present study. ${ }^{19}$ The device was used during infiltration and nerve block techniques of local anesthesia administration, in both the arches. This was contrary to the earlier investigation by Alanazi et al. who included only potentially cooperative children using infiltration technique in the maxillary arch. ${ }^{18}$

Pain is subjective in nature. This study incorporated the SEM scale to assess the pain and discomfort, and significantly lower scores were obtained in the test group thus proving vibration to be an effective tool. Several studies have employed the visual analog scale (VAS) $)^{5,10,22}$ and Wong-Baker pain perception scale ${ }^{1,18}$ to assess pain perceived by a child during local anesthesia These scales could be inaccurate or unreliable due to the inherent fear and apprehension associated with the procedure or dental visit per 
se. The SEM scale focuses on the child's sounds, ocular and motor changes as observed by the dentist, thus masking the confounding factors associated with child's perception of pain and discomfort. ${ }^{21}$

The impact of vibration is based on the gate control theory which suggests that the pain experience can be reduced by activating nerve fibers that conduct non-noxious stimuli. The spinal cord contains a neurologic gate that either blocks pain signals or permits them to travel up the spinothalamic tract to the brain. ${ }^{11}$ Pain sensation travels through unmyelinated $A-\delta$ nerve fibers at a velocity of $6-30 \mathrm{~m} / \mathrm{s}$ and C fibers at a velocity of $0.5-2$ $\mathrm{m} / \mathrm{s}$ whereas vibration stimulus travels at a velocity of $30-70 \mathrm{~m} / \mathrm{s}$ through myelinated $A-\beta$ fibers. ${ }^{20,25}$ In this study, using a vibration stimulus, it was determined whether $A-\beta$ nerve fibers which exhibit a larger diameter and a faster conduction velocity would inhibit the $A-\delta$ and $C$ fibers.

Additionally, according to Melzack, maximum pain reduction occurs when the source of vibration is not just applied to the affected area but stimulates the underlying bone. ${ }^{11}$ This has been supported by Nanitsos, that vibration stimulates the mechanoreceptors, such as the Pacinian corpuscles, Meissner's corpuscles in the skin, subcutaneous tissue, and underlying bone, ${ }^{20}$ thus further supporting the enhanced the efficacy of the device used in this study. Tactile or Meissner's corpuscles are sensitive to light touch and in particular exhibit the highest sensitivity while sensing vibrations between $10 \mathrm{~Hz}$ and $50 \mathrm{~Hz} .{ }^{25}$ The device used in this study operated on a frequency of $50 \mathrm{~Hz}$, thus explaining its effectiveness in increasing the pain threshold.

Distraction has a pivotal impact in diverting attention, especially in children. According to Whelan et al., vibrating devices are effective in distracting pediatric patients and masking the pain of intramuscular injections and venepuncture. ${ }^{15}$ The American Academy of Pediatric Dentistry states that distraction can be effective in decreasing the perception of unpleasantness associated with a procedure and can help to avert negative behavior. ${ }^{26}$ Therefore, even in this study, psychologically children would have been benefited from the vibration stimulation as a novel sensation providing distraction from the injection.

Therefore, in comparison to the other commercially available vibratory devices, this device could prove to be more cost-effective for routine use.

However, the results of this study are too primitive to be generalized, thus warranting further studies to be carried out, on a larger number of children.

\section{Conclusion}

Extraoral application of an innovative vibrating device in children significantly reduced discomfort associated with the administration of local anesthesia.

\section{References}

1. Ching $D$, Finkelman $M$, Loo CY. Effect of the DentalVibe injection system on pain during local anesthesia injections in adolescent patients. Pediatr Dent 2014;36(1):51-55.

2. Van Wijk AJ, Hoogstraten J. Anxiety and pain during dental injections. J Dent 2009;37(9):700-704. DOI: 10.1016/j.jdent.2009.05.023.

3. Czarnecki ML, Turner HN, Collins PM, et al. Procedural pain management: a position statement with clinical practice recommendations. Pain Manag Nurs 2011;12(2):95-111. DOI: 10.1016/j. pmn.2011.02.003.

4. Raadal M, Lundeberg S, Haukali G. Pain, pain control, and sedation. In: Koch G, Poulsen S, ed. Pediatric dentistry a clinical approach. 2nd ed., Oxford: A John Wiley \& Sons, Ltd., Publication; 2009. pp. 44-60.
5. Roeber B, Wallace DP, Rothe V, et al. Evaluation of the effects of the VibraJect attachment on pain in children receiving local anesthesia. Pediatr Dent 2011;33(1):46-50.

6. Jackson $D, C$ hen $A H$, Bennett CR. Identifying true lidocaine allergy. Jam Dent Assoc 1994;125(10):1362-1366. DOI: 10.14219/jada. archive.1994.0180.

7. Garretson LK, McGee EB. Rapid onset of seizures following aspiration of viscous lidocaine. J Pediatr 1992;30(3):413-422. DOI: 10.3109/15563659209021556.

8. Şermet Elbay Ü, Elbay M, Yıldırım S, et al. Evaluation of the injection pain with the use of DentalVibe injection system during supraperiosteal anaesthesia in children: a randomised clinical trial. Int J Paediatr Dent 2016;26(5):336-345. DOI: 10.1111/ipd. 12204.

9. Bross DC. Managing pediatric dental patients: issues raised by the law and changing views of proper child care. Pediatr Dent 2004;26(2):125-130.

10. Kandiah P, Tahmassebi JF. Comparing the onset of maxillary infiltration local anaesthesia and pain experience using the conventional technique vs. the wand in children. Br Dent J 2012;213(9):E15. DOI: 10.1038/sj.bdj.2012.988.

11. Melzack R, Wall PD. Pain mechanisms: a new theory. Science 1965;150(3699):971-979. DOI: 10.1126/science.150.3699.971.

12. Barr ML. The human nervous system: an anatomic viewpoint. 3 rd ed., New York: Harper and Row; 1979. pp. 229-247.

13. Ekblom A, Hansson P. Effects of vibratory stimulation on pain threshold of the human tooth. Acta Physiol Scand 1982;114(4):601604. DOI: 10.1111/j.1748-1716.1982.tb07030.x.

14. Baxter AL, Cohen LL, McElvery HL, et al. An integration of vibration and cold relieves venipuncture pain in a pediatric emergency department. Pediatr Emerg Care 2011;27(12):1151-1156. DOI: 10.1097/ PEC.0b013e318237ace4.

15. Whelan HM, Kunselman AR, Thomas NJ, et al. The impact of a locally applied vibrating device on outpatient venipuncture in children. Clinl Pediatr 2014;53(12):1189-1195. DOI: 10.1177/0009922814538494.

16. Canbulat N, Ayhan F, Inal S. Effectiveness of external cold and vibration for procedural pain relief during peripheral intravenous insertion in pediatric patients. Pain Manag Nurs 2015;16(1):33-39. DOI: 10.1016/j.pmn.2014.03.003.

17. Canbulat N, Şahiner N, Inal S, et al. The effect of combined stimulation of external cold and vibration during immunization on pain and anxiety levels in children. J Perianesth Nurs 2015;30(3):228-235. DOI: 10.1016/j.jopan.2014.05.011.

18. Alanazi KJ, Pani S, AIGhanim N. Efficacy of external cold and a vibrating device in reducing discomfort of dental injections in children: a split mouth randomised crossover study. Eur Arch of Paediatr Dent 2018;1-6.

19. Frankl SN, Shiere FR, Fogels HR. Should the parent remain with the child in the dental operatory? J Dent Child 1962;29:150-163.

20. Nanitsos E, Vartuli R, Forte A, et al. The effect of vibration on pain during local anaesthesia injections. Aust Dent J 2009;54(2):94-100. DOI: 10.1111/j.1834-7819.2009.01100.x.

21. Wright GZ, Weinberger SJ, Marti R, et al. The effectiveness of infiltration anesthesia in the mandibular primary molar region. Pediatr Dent 1991;13(5):278-283.

22. Chaudhry K, Shishodia M, Singh C, et al. Comparative evaluation of pain perception by vibrating needle (Vibraject ${ }^{T M}$ ) and conventional syringe anesthesia during various dental procedures in pediatric patients: a short study. Int Dent Med J Adv Res 2015;1(1):1-5.

23. Casamassimo F, Mctigue N. Pediatric dentistry: infancy through adolescence. 5th ed., Elsevier; 2013. p. 19.

24. Fredrikson M, Annas P, Fischer $\mathrm{H}$, et al. Gender and age differences in the prevalence of specific fears and phobias. Behav Res Ther 1996;34(1):33-39. DOI: 10.1016/0005-7967(95)00048-3.

25. Hall JE, Guyton JM. A textbook of medical physiology. Elsevier Health Sciences; 2015. p. 572.

26. American Academy of Pediatric Dentistry. Behavior guidance for the pediatric dental patient. Pediatr Dent 2017;39(6):246-259. 